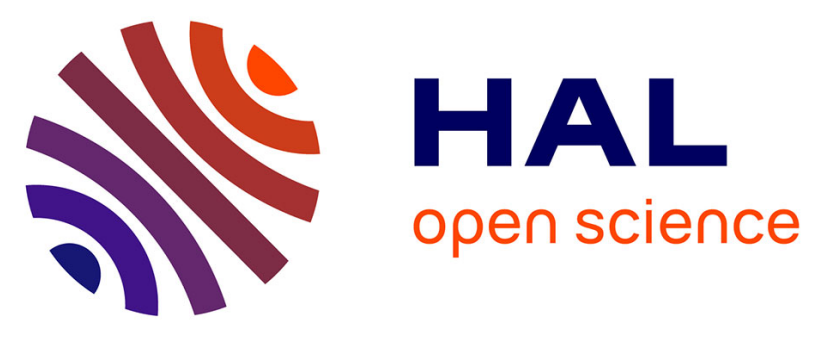

\title{
Idelalisib treatment prior to allogeneic stem cell transplantation for patients with chronic lymphocytic leukemia: a report from the EBMT chronic malignancies working party
}

Johannes Schetelig, Patrice Chevallier, Michel van Gelder, Jennifer Hoek, Olivier Hermine, Ronjon Chakraverty, Paul Browne, Noel Milpied, Michele Malagola, Gerard Socié, et al.

\section{- To cite this version:}

Johannes Schetelig, Patrice Chevallier, Michel van Gelder, Jennifer Hoek, Olivier Hermine, et al.. Idelalisib treatment prior to allogeneic stem cell transplantation for patients with chronic lymphocytic leukemia: a report from the EBMT chronic malignancies working party. Bone Marrow Transplantation, 2020, 56 (3), pp.605 - 613. 10.1038/s41409-020-01069-w . inserm-03549845

\author{
HAL Id: inserm-03549845 \\ https://www.hal.inserm.fr/inserm-03549845
}

Submitted on 31 Jan 2022

HAL is a multi-disciplinary open access archive for the deposit and dissemination of scientific research documents, whether they are published or not. The documents may come from teaching and research institutions in France or abroad, or from public or private research centers.
L'archive ouverte pluridisciplinaire $\mathbf{H A L}$, est destinée au dépôt et à la diffusion de documents scientifiques de niveau recherche, publiés ou non, émanant des établissements d'enseignement et de recherche français ou étrangers, des laboratoires publics ou privés. 


\title{
Idelalisib treatment prior to allogeneic stem cell transplantation for patients with chronic lymphocytic leukemia: a report from the EBMT chronic malignancies working party
}

\author{
Johannes Schetelig $\mathbb{1}^{1,2} \cdot$ Patrice Chevallier ${ }^{3}$ - Michel van Gelder ${ }^{4}$ Jennifer Hoek ${ }^{5}$ - Olivier Hermine ${ }^{6}$. \\ Ronjon Chakraverty ${ }^{7} \cdot$ Paul Browne $^{8} \cdot$ Noel Milpied $^{9} \cdot$ Michele Malagola $^{10} \cdot$ Gerard Socié $^{11} \cdot$ Julio Delgado $^{12}$. \\ Eric Deconinck ${ }^{13}$. Ghandi Damaj ${ }^{14}$. Sebastian Maury ${ }^{15}$. Dietrich Beelen ${ }^{16}$. Stéphanie Nguyen Quoc ${ }^{17}$. \\ Paneesha Shankara $^{18} \cdot$ Arne Brecht $^{19}$ - Jiri Mayer ${ }^{20} \cdot{\text { Mathilde Hunault-Berger } \mathbb{D}^{21} \text { - Jörg Bittenbring }}^{22}$. \\ Catherine Thieblemont ${ }^{23} \cdot$ Stéphane Lepretre ${ }^{24} \cdot$ Henning Baldauf $^{2} \cdot$ Liesbeth C. de Wreede $^{25} \cdot$ Olivier Tournilhac $^{26}$. \\ Ibrahim Yakoub-Agha ${ }^{27} \cdot$ Nicolaus Kröger $\mathbb{B}^{28} \cdot$ Peter Dreger $\mathbb{B}^{29}$
}

Received: 25 March 2020 / Revised: 15 September 2020 / Accepted: 18 September 2020 / Published online: 2 October 2020

(c) The Author(s) 2020. This article is published with open access, corrected publication 2021

\begin{abstract}
No studies have been reported so far on bridging treatment with idelalisib for patients with chronic lymphocytic leukemia (CLL) prior to allogeneic hematopoietic cell transplantation (alloHCT). To study potential carry-over effects of idelalisib and to assess the impact of pathway-inhibitor (PI) failure we performed a retrospective EBMT registry-based study. Patients with CLL who had a history of idelalisib treatment and received a first alloHCT between 2015 and 2017 were eligible. Data on 72 patients (median age 58 years) were analyzed. Forty percent of patients had TP53 $3_{\text {mut/del }}$ CLL and $64 \%$ had failed on at least one PI. No primary graft failure occurred. Cumulative incidences of acute GVHD ${ }^{\circ} \mathrm{II}-\mathrm{IV}$ and chronic GVHD were $51 \%$ and $39 \%$, respectively. Estimates for 2-year overall survival (OS), progression-free survival (PFS), and cumulative incidences of relapse/progression (CIR) and non-relapse mortality NRM were 59\%, 44\%, 25\%, and 31\%. In univariate analysis, drug sensitivity was a strong risk factor. For patients who had failed neither PI treatment nor chemoimmunotherapy (CIT) the corresponding 2-year estimates were $73 \%, 65 \%, 15 \%$, and $20 \%$, respectively. In conclusion, idelalisib may be considered as an option for bridging therapy prior to alloHCT. Owing to the high risk for acute GVHD intensified clinical monitoring is warranted.
\end{abstract}

\section{Introduction}

Pathway inhibitors (PI) such as BTK-inhibitors (BTKi), PI3Kinase inhibitors (PI3Ki), and BCL2-inhibitors (BCL2i) have fundamentally transformed the standard treatment landscape for chronic lymphocytic leukemia (CLL) in recent years. Since these drugs target different signaling pathways, CLL is usually not cross-resistant to different PIs. PIs can thus be administered sequentially [1-4]. Multiple sequences are perceivable in which BTKi and BCL2i are favored for first- and second line treatment [5-7].

Johannes Schetelig

johannes.schetelig@uniklinikum-dresden.de

Extended author information available on the last page of the article
The phosphatidylinositol 3-kinase (PI3K 8 )-inhibitor, idelalisib, can be active also in BTKi-refractory and BCL2irefractory CLL $[1,5,7]$, and thus might be an option for bridging into allogeneic hematopietic cell transplantation (alloHCT). The PI3-kinase exerts pleiotropic effects on cell metabolism, migration, proliferation, survival, and differentiation in lymphoid tissues. Autoimmune-mediated side effects such as colitis, hepatitis, and pneumonitis have been reported on treatment with idelalisib [8,9]. Exposure to idelalisib could thus interfere with subsequent alloHCT. Patients who had received idelalisib for CLL prior to alloHCT have not been studied systematically so far.

Therefore, we analyzed the outcome of patients with CLL who had received idelalisib prior to alloHCT. In order to evaluate potential carry-over effects of idelalisib pretreatment on outcome after alloHCT we focused on early events after alloHCT such as engraftment, occurrence of GVHD and relapse as well as NRM throughout the first year 
after alloHCT. Here, we report final results from this EBMT registry study.

\section{Patients and methods}

\section{Study design and patient eligibility}

The study was designed as a registry-based retrospective multicenter study. Eligibility criteria were age 18 years or above, a first alloHCT for CLL between January 2015 and December 2017, and treatment with idelalisib at any time before transplant. Patients with a history of Richter transformation or syngeneic transplantation were excluded.

Since specific drug exposure was not routinely reported on Minimal Essential Data A (MED-A) forms during the beginning of this study, a survey was sent to all EBMT centers performing alloHCT in order to identify eligible patients. Baseline patient, disease, and transplant data of consecutive patients who were indicated by participating centers as meeting the eligibility criteria for this study were collected from MED-A forms.

The study was conducted by the EBMT Chronic Malignancies and Lymphoma Working Parties. All patients signed informed consent for the collection and registrybased analysis of their medical data. The study was conducted in full compliance with the declaration of Helsinki.

\section{Data management}

For registered patients, baseline information, characteristics of the transplant procedure, and outcome data were collected on standard MED-A forms of EBMT. CLL with multiple cytogenetic abnormalities was classified according to the standard hierarchical approach [10]. Sensitivity of CLL to chemoimmunotherapy (CIT) was grouped in a modified way of the original definitions [11]. Patients whose CLL was responsive to CIT and did not require retreatment for relapse within 2 years were classed as having CIT-sensitive CLL. Refractoriness to CIT or re-treatment within 2 years was classed as CIT-refractory CLL. Doseintensity of the conditioning regimen was classified according to consensus working definitions of EBMT and CIBMTR [12].

\section{Statistical analysis}

The primary aim of the analysis was to describe engraftment, GVHD, and events during the first year after alloHCT. Events for progression-free survival (PFS) were clinical relapse, progression, or death. Immune manipulations such as the taper of immunosuppressive drugs, the administration of donor lymphocyte infusions or the administration of rituximab were not considered as events for RFS. Non-relapse mortality (NRM) was defined as death without preceding clinical relapse/progression after alloHCT.

Data were analyzed as of September 20, 2019. Curves for RFS and overall survival (OS) were calculated using the Kaplan-Meier method and compared by log-rank tests. Incidences of relapse and NRM were calculated using cumulative incidence statistics and between-group comparisons were performed with the Gray test [13]. The impact of the occurrence GVHD (acute GVHD grades II to IV or any grade of chronic GVHD) on the incidence of relapse was tested in a time-dependent Cox-regression model. All point estimates for time-to-event endpoints are reported together with approximate 95\%-confidence intervals.

\section{Results}

\section{Patient characteristics}

Altogether 72 patients met the eligibility criteria and had a full dataset available for this study.

Patient characteristics are shown in Table 1. Fifty-one male and 21 female patients were enrolled. The median age was 58 years (range, 36-73 years). Karnofsky Performance Score ranged between $80 \%$ and $100 \%$ for $98 \%$ of patients. The median reported Hematopoietic Cell TransplantationComorbidity Index was 0 (range: $0-6$ ) but $16 \%$ of patients had a score $\geq 3$.

The median interval between diagnosis of CLL and alloHCT was 7 years (range, 1-19 years), and the median time from first treatment of CLL to alloHCT was 51 months (range, 4 months to 17 years). Twenty-nine patients (40\%) had a deletion TP53 mutation or deletion, seven patients (10\%) had a deletion(11q) but no TP53 mutation or deletion.

\section{Pre-treatment}

By definition, all 72 patients had been exposed to idelalisib prior to alloHCT. Of those, 48 patients (67\%) had received idelalisib as bridge to transplant. Twenty-two (46\%) of these 48 patients had failed already at least one other PI. The interval between the last dose of idelalisib and alloHCT ranged between a minimum of 6 days and a maximum of 17 months with a median number of 24 days. In total, 16 patients had received their last dose of idelalisib within the last month prior to alloHCT. The response rate prior to alloHCT was $75 \%$ (36 out of 48 patients) among patients whose last line of treatment contained idelalisib. Regarding disease status prior to conditioning of all 72 patients, five patients $(7 \%)$ were in complete remission, 54 patients $(77 \%)$ 
Table 1 Patient characteristics.

\begin{tabular}{|c|c|}
\hline & $\begin{array}{l}\text { Numbers of } \\
\text { patients }(\%) \\
\text { Total, } N=72\end{array}$ \\
\hline Median age at HCT [years] (range) & $58(36-73)$ \\
\hline Patients older than 60 years & $27(38)$ \\
\hline Female & $21(29)$ \\
\hline Male & $51(71)$ \\
\hline \multicolumn{2}{|l|}{ Karnofsky index at HCT } \\
\hline $100 \%$ & $29(44)$ \\
\hline $90 \%$ & $22(33)$ \\
\hline $80 \%$ & $14(21)$ \\
\hline $70 \%$ & $1(2)$ \\
\hline Median HCT-CI (range) ${ }^{\mathrm{a}}$ & $0(0-6)$ \\
\hline Patients with HCT-CI $\geq 3$ & $8(11)$ \\
\hline \multicolumn{2}{|l|}{ Cytogenetic abnormalities } \\
\hline$T P 53_{\mathrm{del} / \mathrm{mut}}$ & $29(40)$ \\
\hline $\operatorname{Deletion}(11 \mathrm{q}) /$ no $T P 53_{\mathrm{del} / \mathrm{mut}}$ & $7(10)$ \\
\hline Other/no del(11q), no $T P 53_{\mathrm{del} / \mathrm{mut}}$ & $13(18)$ \\
\hline None & $23(32)$ \\
\hline Previous lines of therapies, median (range) & $3(1-8)$ \\
\hline \multicolumn{2}{|l|}{ Idelalisib } \\
\hline Median duration in months (range) & $6(1-28)$ \\
\hline Idelalisib as last line prior to $\mathrm{HCT}$ & $48(67)$ \\
\hline $\begin{array}{l}\text { Idelalisib during course of CLL but } \\
\text { not as last line }\end{array}$ & $24(33)$ \\
\hline \multicolumn{2}{|l|}{ Drug exposure for CLL treatment, $N$ of patients } \\
\hline Chemotherapy naive & $20(28)$ \\
\hline Purine analogue therapy & $41(57)$ \\
\hline Ibrutinib & $31(43)$ \\
\hline Venetoclax & $13(18)$ \\
\hline Alemtuzumab & $10(14)$ \\
\hline \multicolumn{2}{|l|}{ Chemoimmunotherapy sensitivity } \\
\hline Not exposed & $19(26)$ \\
\hline Sensitive disease & $33(45)$ \\
\hline Poorly responsive/refractory ${ }^{\mathrm{b}}$ & $20(27)$ \\
\hline Failure of at least one pathway inhibitor & $46(64)$ \\
\hline \multicolumn{2}{|l|}{ Status at HCT } \\
\hline Complete remission & $5(7)$ \\
\hline Partial remission & $54(77)$ \\
\hline Stable or progressive disease & $11(15)$ \\
\hline \multicolumn{2}{|l|}{ Donor type } \\
\hline HLA-identical sibling & $21(29)$ \\
\hline Other (partially) matched related donor & $10(14)$ \\
\hline 8/8 HLA-compatible unrelated donor (UD) & $25(35)$ \\
\hline HLA-compatible UD, HLA data missing & $12(17)$ \\
\hline Partially matched UD & $4(6)$ \\
\hline \multicolumn{2}{|l|}{ CMV constellation } \\
\hline Donor and recipient CMV neg. & $19(27)$ \\
\hline Donor or recipient CMV pos. & $52(73)$ \\
\hline
\end{tabular}

Table 1 (continued)

\begin{tabular}{lc}
\hline & $\begin{array}{c}\text { Numbers of } \\
\text { patients }(\%) \\
\text { Total, } N=72\end{array}$ \\
\hline Sex constellation & $10(14)$ \\
Female patient-female donor & $11(16)$ \\
Female patient-male donor & $14(20)$ \\
Male patient-female donor & $35(50)$ \\
Male patient-male donor & \\
Conditioning regimen & $11(15)$ \\
Non-myeloablative based on 2 Gray TBI & $47(65)$ \\
Reduced intensity & $14(19)$ \\
High-dose therapy & \\
Stem cell source & $67(93)$ \\
Peripheral blood stem cells & $4(6)$ \\
Bone marrow & $1(1)$ \\
Cord blood & \\
GVHD prophylaxis & $62(86)$ \\
CSA with/without MTX/MMF & $8(11)$ \\
Tacrolimus with/without MTX/MMF & $2(3)$ \\
Other & $39(54)$ \\
ATG & $9(13)$ \\
PTCY & $9(13)$ \\
Alemtuzumab &
\end{tabular}

$N$ number, $H C T$ hematopoietic cell transplantation, $H C T$ - $C I$ hematopoietic cell transplantation-comorbidity index, $C M V$ cytomegalovirus, $G V H D$ graft-versus-host disease, $T B I$ total body irradiation, $C S A$ cyclosporine A, MTX methotrexate, $M M F$ mycophenolate mofetil, $P B S C$ peripheral blood stem cells, $A T G$ anti-thymocyte globulin, $P T C Y$ posttransplant cyclophosphamide.

${ }^{a}$ Information on the HCT-CI was not available for 22 patients.

${ }^{\mathrm{b}}$ No response or re-treatment within 24 months.

were in partial remission, and 11 patients had stable/ progressive CLL. The remission status was unknown for two patients.

Overall, the majority of patients had advanced disease stages reflected by a median number of 3 (range, 1-8) lines of therapy prior to alloHCT. Forty-five percent of patients had CIT-refractory disease. As for PI treatment, $43 \%$ had been exposed to ibrutinib and $18 \%$ to venetoclax during their course of CLL. Altogether, $64 \%$ of patients had failed one or more PIs. Eight patients (11\%) had received three PIs (idelalisib, ibrutinib, and venetoclax) prior to alloHCT.

Of note, 20 patients (27\%) had received only PI with or without monoclonal antibodies but no chemotherapy for the treatment of CLL. This subset exposed high-risk genetic features, with $75 \%$ of patients having TP53 $3_{\text {mut/del }}$ CLL and $45 \%$ having failed at least on one PI, so that the median number of pre-treatments was still 2 (range, 1-4 lines of pretreatment). 


\section{Transplant procedure}

Forty-seven patients (65\%) received reduced-intensity conditioning based on combinations of fludarabine and either busulphan, melphalan, or cyclophosphamide or total body irradiation (TBI) at cumulative doses between 2 and 8 Grays. Eleven patients (15\%) received non-myeloablative conditioning based on TBI with 2 Gray and 14 patients (19\%) received myeloablative conditioning.

Twenty-one patients (29\%) received hematopoietic stem cells from their HLA-compatible siblings. Ten patients (14\%) had other related donors (partially matched/haploidentical) and 41 patients (57\%) had HLA-compatible unrelated donors, including four patients whose donors had a single HLA mismatch at HLA-A, -B, -C, or HLADRB1. The exact HLA-matching status was missing for 12 unrelated patient-donor pairs.

G-CSF mobilized peripheral blood stem cells were transplanted to 67 patients (93\%), four patients received bone marrow and one patient cord blood. No patient received an in vitro T-cell depleted stem cell graft. GVHD prophylaxis was based on calcineurin inhibitor for 71 patients (97\%). In addition 39 patients (54\%) had received anti-thymocyte globulin (ATG), and nine patients (13\%) each alemtuzumab or high-dose cyclophosphamide, respectively.

\section{Engraftment and GVHD}

All patients showed primary engraftment. The median time to neutrophil engraftment was 17 days (range, 9-40 days). For platelet engraftment to greater than $20 \mathrm{GPt} / \mathrm{L}$ a median number of 16 days (range, 1-50 days) was reported. Two cases of secondary graft failure were observed in the context of continuous progression and a lethal infection in one patient each. Transient graft failure was reported for two patients. Idelalisib was the last line of treatment only in two of these four cases of secondary graft failure.

The cumulative incidences of acute GVHD grades II-IV and grades III-IV at 100 days after alloHCT were $51 \%$ (95\%CI, 39-63\%) and 24\% (95\%-CI, 13-34\%), respectively. The cumulative incidence of acute GVHD grades II-IV was $63 \%$ (95\%-CI, 37-88\%) among 16 patients whose last dose of idelalisib was within 28 days prior to alloHCT. Seventy patients were evaluable for chronic GVHD. The cumulative incidence of limited or extensive chronic GVHD at 1 year after alloHCT was 39\% (95\%-CI, 27-51\%).

\section{Overall survival, progression-free survival, relapse, and non-relapse mortality}

At last follow-up, 44 patients were alive with a median observation time of 21 months (range, 3-50 months). The
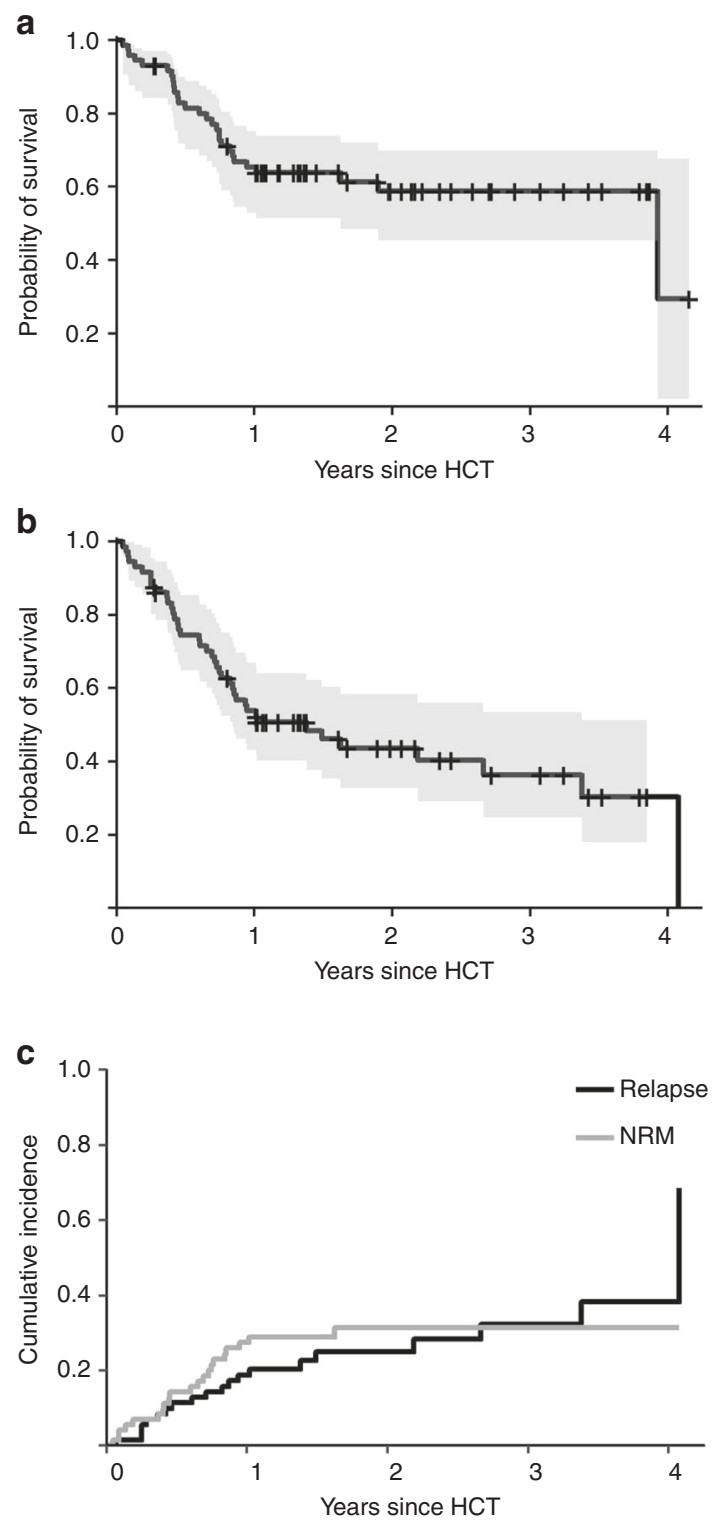

Fig. 1 Outcome after alloHCT for patients with CLL who have been exposed to idelalisib. a, b Shows overall and progression-free survival with point-wise $95 \%$-confidence intervals, respectively. c Shows the cumulative incidences of relapse and non-relapse mortality.

probability of overall and PFS at 2 years was 59\% (95\%-CI, $45-70 \%)$ and $44 \%$ (95\%-CI, 33-58\%), respectively (Fig. 1a, b). Altogether 20 patients were reported to have experienced relapse or progression. The cumulative incidence of relapse at 2 years was $25 \%$ (95\%-CI, 14-36\%) (Fig. 1c). After relapse/progression, ibrutinib was administered to seven patients, venetoclax to four patients, and idelalisib to one patient. One patient received all three drugs after having experienced relapse but died 47 months after alloHCT. Two patients received venetoclax after alloHCT without previous hematologic relapse/progression as maintenance therapy. 
Twenty-one patients died without previous relapse. Main causes of death were infections $(N=8)$, GVHD $(n=7)$, organ failure $(N=2)$, and a secondary malignancy $(N=1)$. Causes of death were not reported for three patients. The cumulative incidence of NRM at 2 years was $31 \%(95 \%-\mathrm{CI}$, 20-43\%) (Fig. 1c). Notably, no patient whose last dose of idelalisib was within 28 days prior to alloHCT died within the first 100 days after alloHCT.

\section{Univariable comparisons}

In exploratory univariable analyses, age, HCT-CI, number of prior treatment lines, remission status, and donor type did not have a significant impact on OS, PFS, NRM, and CIR (see Table 2).

First, we analyzed PFS by grouping patients according to the type of pretreatment and disease sensitivity (see Fig. 2a-c). Sensitivity to CIT prior to conditioning had a significant impact on PFS in univariable comparison (logrank test, $p=0.03$ ). Patients with CIT-naive CLL had 2year PFS of $64 \%$ (95\%-CI, 39-89\%), patients with CITsensitive CLL had 2-year PFS of 50\% (95\%-CI, 26-74\%), and patients with CIT-refractory CLL had 32\% (95\%-CI, 14-50\%) (Fig. 2a).

Patients who had PI-sensitive disease had better 2-year PFS compared to patients who had failed at least one PI (67\% (95\% CI, 47-87\%) versus 30\% (95\% CI, 14-46\%), log-rank test, $p=0.01$ ) (Fig. 2b). Notably, owing to the design of this study all patients with PI-sensitive CLL were sensitive to idelalisib. In contrast, of eight patients who had been exposed to all three PIs (BTKi, BCL2i, and PI3K) and had failed on two PIs only two patients $(25 \%)$ did not experience relapse $(N=3,37.5 \%)$ or $\operatorname{NRM}(N=3,37.5 \%)$ during the first year after HCT.

Finally, we analyzed the impact of high-risk genetic abnormalities in this cohort of patients. Two-year PFS was 86\% (95\% CI, 73-100\%) for patients with TP53 $3_{\mathrm{del} / \mathrm{mut}}$ CLL versus compared to $28 \%(95 \% \mathrm{CI}, 17-47 \%)$ for the remaining patients (Log-rank test, $p=0.002$ ). Of note in this context, patients with $T P 53_{\mathrm{del} / \mathrm{mut}}$ more often had chemotherapy-naive CLL prior to the start of conditioning compared to patients without $T P 53_{\mathrm{del} / \text { mut }}$ CLL (88\% versus $48 \%$, chi-square test $p<0.001)$ although the percentage of patients who had failed at least one PI was not significantly different among the two groups (55 versus 69\%, respectively, chi-square test $p=0.2$ ).

\section{Discussion}

We present results of a large cohort of contemporary patients with who received alloHCT for high-risk CLL after pretreatment with idelalisib. This cohort of patients had two unique features: First, it is the largest cohort published so far of patients who failed on one or two PIs and subsequently proceeded to alloHCT. Second, it comprises a large number of patients whose CLL was chemotherapy naive at alloHCT. Results of this retrospective, EBMT registrybased study allow for a discussion of the risk-benefit ratio of idelalisib as a bridging treatment prior to alloHCT andfrom a broader perspective-to reason about contemporary indications for alloHCT for CLL.

Safety of idelalisib treatment prior to alloHCT has been a concern due to the observation of autoimmune-mediated diseases, resulting in severe colitis, pneumonitis, and hepatitis, which may occur during idelalisib treatment [8]. Experimental data suggest that PI3K delta inhibitors, such as idelalisib, partly mediate their activity by disrupting the function of immunosuppressive cell populations such as $T_{\text {regs }}$ and MDSCs [14]. Thereby idelalisib may shift the balance from immune tolerance toward effective antitumor immunity [15]. Idelalisib may thus exert direct and indirect action on tumor cells but also unleash autoimmune reactions. Potential carry-over effects of a pretreatment with idelalisib were therefore a valid concern. Overall, the cumulative incidences of $51 \%$ grades II-IV acute GVHD and $39 \%$ chronic GVHD observed here are comparable to recent publications on alloHCT for contemporary patients with CLL [16-18]. E.g. after pretreatment with ibrutinib cumulative incidences of $49 \%$ grades II-IV acute GVHD and 54\% chronic GVHD were reported [17] and recently for patients who received conditioning with fludarabine and low-dose TBI combined with rituximab cumulative incidences of $69 \%$ grades II-IV acute GVHD and $66 \%$ chronic GVHD were published [18]. Still, the observation that $63 \%$ of patients experienced grades II-IV acute GVHD who had taken their last dose of idelalisib within 28 days to alloHCT indicates that this patient population is at high risk of GVHD owing to multiple factors, e.g., due to frequent partially mismatched related and unrelated transplantation.

Little information is available on the safety of idelalisib in the context of alloHCT. Sellner et al. reported EBMT registry data from 33 patients with follicular lymphoma who had received idelalisib for bridging to alloHCT [19]. They found no increased incidence of acute GVHD compared to patients who had received other treatment regimens prior to alloHCT but also reported a considerable incidence of severe acute GVHD (24\% acute GVHD grades III-IV) in this patient population. On the other hand, Dreger et al. analyzed registry data on 24 patients with predominantly Bcell malignancies who had received idelalisib for the treatment of relapse after alloHCT and reported de novo GVHD or aggravation of preexisting GVHD in only one patient in whom idelalisib had been initiated as early as 30 days after alloHCT [20]. Taken together, currently available data are not robust enough to preclude an increased risk of GVHD 
Table 2 Univariable analysis of overall- and relapse-free survival, relapse incidence and non-relapse mortality.

\begin{tabular}{|c|c|c|c|c|c|c|c|c|c|}
\hline Variables & $N$ & $\begin{array}{l}\text { 2-year OS } \\
(95 \% \mathrm{CI})\end{array}$ & $p$ value & $\begin{array}{l}\text { 2-year PFS } \\
(95 \% \mathrm{CI})\end{array}$ & $p$ value & $\begin{array}{l}\text { 2-year CIR } \\
(95 \% \mathrm{CI})\end{array}$ & $p$ value & $\begin{array}{l}\text { 2-year NRM } \\
(95 \% \mathrm{CI})\end{array}$ & $p$ value \\
\hline Whole cohort & 72 & $59(45-70)$ & & $44(33-58)$ & & $25(14-36)$ & & $31(20-43)$ & \\
\hline \multicolumn{10}{|l|}{ Patient age at HCT } \\
\hline$<60$ years & 45 & $66(52-83)$ & 0.13 & $52(39-70)$ & 0.13 & $24(11-38)$ & 0.62 & $23(10-36)$ & 0.11 \\
\hline$\geq 60$ years & 27 & $47(30-74)$ & & $28(14-58)$ & & $26(6-46)$ & & $45(23-68)$ & \\
\hline \multicolumn{10}{|l|}{ HCT-CI, score } \\
\hline$<3$ & 42 & $52(36-73)$ & 0.45 & $40(26-61)$ & 0.49 & $22(8-36)$ & 0.72 & $38(21-55)$ & 0.54 \\
\hline$\geq 3$ & 8 & $50(25-100)$ & & $38(15-92)$ & & $25(0-58)$ & & $38(0-75)$ & \\
\hline \multicolumn{10}{|l|}{ Presence of $T P 53_{\mathrm{mut} / \mathrm{del}}$ CLL } \\
\hline Present & 29 & $86(73-100)$ & 0.001 & $68(51-90)$ & 0.002 & $25(6-44)$ & 0.46 & $7(0-17)$ & 0.001 \\
\hline Absent & 43 & $42(29-61)$ & & $28(17-47)$ & & $25(11-39)$ & & $47(31-63)$ & \\
\hline \multicolumn{10}{|c|}{ Status with respect to chemotherapy } \\
\hline Chemo-naive CLL & 20 & $73(55-96)$ & 0.16 & $64(44-94)$ & 0.02 & $14(0-34)$ & 0.06 & $21(2-41)$ & 0.16 \\
\hline Chemo-exposed CLL & 51 & $52(39-70)$ & & $38(26-55)$ & & $27(14-39)$ & & $36(22-50)$ & \\
\hline \multicolumn{10}{|l|}{ Status with respect to PI } \\
\hline $\begin{array}{l}\text { No PI failed, Idela } \\
\text { sensitive }\end{array}$ & 26 & $76(61-95)$ & 0.06 & $67(50-89)$ & 0.01 & $17(1-34)$ & 0.13 & $16(1-31)$ & 0.03 \\
\hline$\geq 1$ PI failed & 46 & $48(33-68)$ & & $30(18-50)$ & & $30(15-45)$ & & $41(25-57)$ & \\
\hline \multicolumn{10}{|c|}{ Chemoimmunotherapy sensitivity } \\
\hline Not exposed & 20 & $73(55-96)$ & 0.13 & $64(44-94)$ & 0.03 & $14(0-34)$ & 0.12 & $21(2-41)$ & 0.22 \\
\hline Sensitive disease & 18 & $60(38-95)$ & & $50(32-79)$ & & $22(2-42)$ & & $28(6-49)$ & \\
\hline $\begin{array}{l}\text { poorly responsive/ } \\
\text { refractory }\end{array}$ & 33 & $47(32-70)$ & & $32(19-54)$ & & $29(12-45)$ & & $39(21-58)$ & \\
\hline \multicolumn{10}{|l|}{ Treatment failure status } \\
\hline $\begin{array}{l}\text { Failed neither PI } \\
\text { nor CIT }\end{array}$ & 16 & $73(54-100)$ & 0.003 & $64(43-96)$ & $<0.001$ & $15(0-37)$ & 0.047 & $20(0-41)$ & 0.005 \\
\hline Failed PI either or CIT & 32 & $68(52-90)$ & & $59(44-79)$ & & $19(5-33)$ & & $22(7-37)$ & \\
\hline Failed PI and CIT & 23 & $31(16-62)$ & & $13(4-43)$ & & $33(12-54)$ & & $54(30-78)$ & \\
\hline \multicolumn{10}{|c|}{ Number of lines of pretreatment } \\
\hline$\leq 2$ & 23 & $68(51-91)$ & 0.37 & $56(38-83)$ & 0.13 & $17(0-35)$ & 0.16 & $27(8-47)$ & 0.45 \\
\hline$\geq 3$ & 49 & $54(40-72)$ & & $38(26-56)$ & & $28(15-41)$ & & $34(19-48)$ & \\
\hline \multicolumn{10}{|l|}{ Remission status at alloHCT } \\
\hline $\begin{array}{l}\text { Complete/partial } \\
\text { remission }\end{array}$ & 59 & $62(50-78)$ & 0.09 & $45(33-62)$ & 0.32 & $27(14-40)$ & 0.57 & $28(15-40)$ & 0.053 \\
\hline $\begin{array}{l}\text { Stable/progressive } \\
\text { disease }\end{array}$ & 13 & $42(22-82)$ & & $35(16-76)$ & & $15(0-36)$ & & $50(19-81)$ & \\
\hline \multicolumn{10}{|l|}{ Donor type } \\
\hline HLA-identical sibling & 21 & $58(40-86)$ & 0.68 & $50(32-79)$ & 0.38 & $19(2-36)$ & 0.39 & $31(9-53)$ & 0.70 \\
\hline Alternative donor & 51 & $61(48-76)$ & & $41(28-59)$ & & $28(14-42)$ & & $31(18-44)$ & \\
\hline
\end{tabular}

$O S$ overall survival, $R F S$ relapse-free survival, $R I$ relapse incidence, $N R M$ non-relapse mortality, $C I$ confidence interval, $H C T$ hematopoietic stem cell transplantation, $H C T$-CI hematopoietic cell transplantation-comorbidity index, $p$ values are based on log-rank test (OS and PFS) and Gray's test (CIR and NRM), they compare the curves during the whole follow-up.

after bridging therapy with idelalisib. Therefore, caution should be maintained when idelalisib is used in this vulnerable period, especially with respect to GVHD.

To our knowledge this is the largest cohort of contemporary patients after alloHCT of whom a large proportion had failed at least one PI and/or CIT. The heterogeneity of the pretransplant disease history allowed only for a preliminary univariable risk factor analysis. In this analysis, failure after CIT and/or on a PI was a significant risk factor for PFS. Data from a study on ibrutinib prior to alloHCT for CLL suggested already that PI failure might be a negative risk factor for relapse [17]. However, the observation that patients who had only failed PI treatment but not CIT had better outcomes inspite of TP5 $3_{\mathrm{mut} / \mathrm{del}}$ CLL in $55 \%$ of cases 
a PFS by sensitivity to chemo-immunotherapy

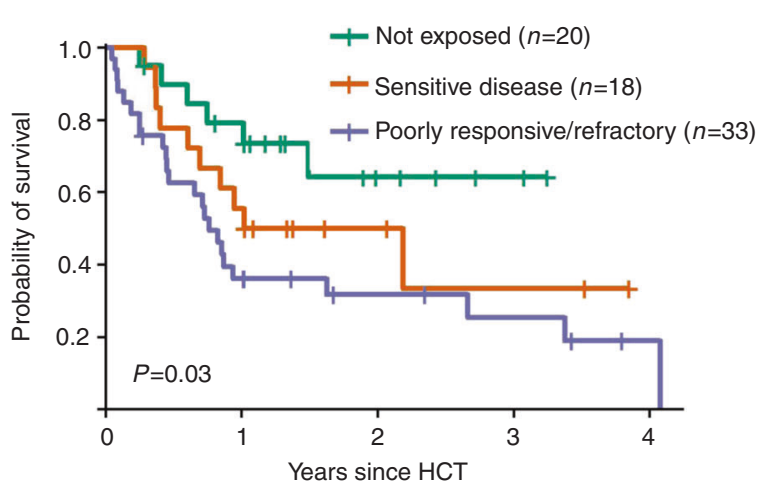

b

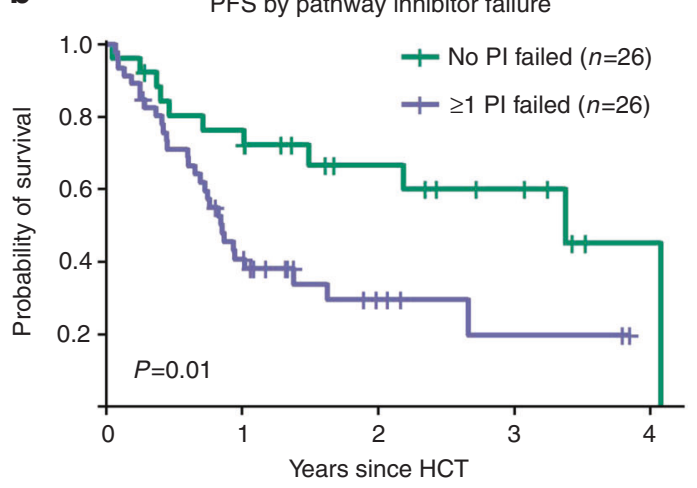

C

PFS by failure to either or both types of treatments

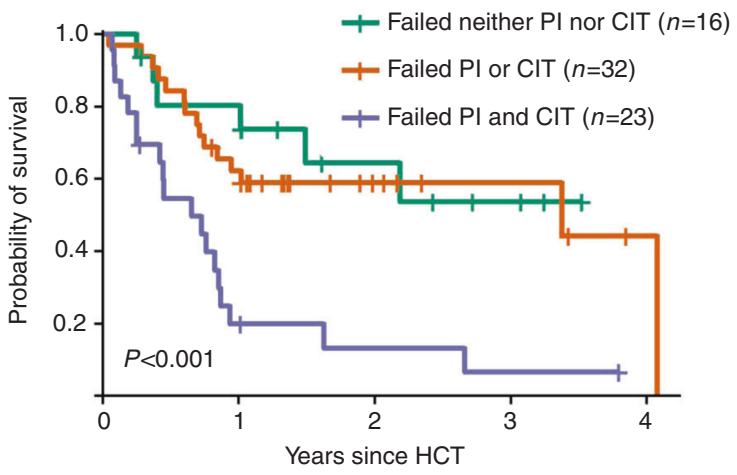

Fig. 2 Univariable comparisons of progression-free survival for selected risk factors were done by log-rank tests. a Shows progression-free survival by sensitivity to chemoimmunotherapy (CIT). Patients who were not exposed to CIT are shown in green, patients with CIT-sensitive CLL in brown and patients with poorly responsive/refractory CLL in violet. b Shows PFS by pathwayinhibitor failure. Patients who had only been exposed to idelalisib and responsive disease are displayed in green, all remaining patients are displayed in violet. c Shows PFS of patients by pathway-inhibitor (PI)or CIT failure. Patients who had failed neither PI nor CIT are shown in green. Patients who had failed either PI or CIT are shown in brown color. The remaining patients (violet curve), who have failed both, CIT and PI, have the worst outcome.

(see Fig. 2c) than patients who had failed PI treatment and CIT inspite of only $17 \%$ of $T P 53_{\text {mut/del }}$ CLL warrants consideration.
Our observations fit to the common principle that results after alloHCT deteriorate the more lines of therapy have been administered prior to transplantation. So while alloHCT should not be delayed, we also would like to stress that the risk-benefit ratio of alloHCT compared to current standard treatment options, does not justify recommendation for alloHCT in first remission and refer to our consensus paper on indications for alloHCT in the era of PIs [21].

Once the decision was made to proceed to an allogeneic HCT, the most potent treatment should be chosen to induce a remission prior to starting conditioning. This recommendation is based on risk factor analyses from multiple studies, where the remission status prior to alloHCT turned out to be a major predictor for long-term disease free survival $[22,23]$. Critical issues for this decision are the treatment history and the presence of mutations which confer resistance to CIT or certain PIs. Venetoclax may have the most attractive risk-benefit ratio for patients with ventoclax-naive or sensitive CLL, because it is well tolerated and MRDnegative responses have been reported even after failure of ibrutinib or idelalisib [2, 3, 5]. However, data on venetoclax-induction immediately prior to alloHCT have not been published yet. Data on the efficacy of idelalisib after failure of PI treatment are sparse. In one retrospective analysis, the overall response rate was $46 \%$ with no complete remission among 37 patients who had received idelalisib after ibrutinib failure [5]. Recently, data on 17 patients were reported who had been treated with PI3Ki after BTKi exposure and failure after venetoclax [7]. Of these patients $47 \%$ achieved a remission, but the median PFS was only 5 months. Based on these data idelalisib may be an option for remission induction prior to alloHCT in e.g., patients with $T P 53_{\text {mut/del }}$ CLL who failed or did not tolerate BTKi and venetoclax.

In conclusion, results from this retrospective study allow for the use of idelalisib for remission induction prior to alloHCT. However, since we cannot exclude immunologic carry-over effects, we recommend stopping idelalisib at least 1 month prior to alloHCT and intensified monitoring for symptoms of acute GVHD.

Our study showed poor outcomes after alloHCT for patients who had failed PIs and CIT during their CLL treatment course. This observation may be used as an argument not to delay alloHCT in fit patients with high-risk CLL who have failed treatment with PIs. Alternatively, for this group of patients enrollment onto clinical trials with new investigational agents or chimeric antigen receptor modified $\mathrm{T}$ cells or NK cells may be an attractive option.

Acknowledgements We wish to thank the patients and their families, the local data managers, and physicians and the staff at the EBMT Data Office in Leiden, who made this study possible. 
Funding Open Access funding enabled and organized by Projekt DEAL.

\section{Compliance with ethical standards}

Conflict of interest JS - consultancy honoraria from AstraZeneca, Janssen, Roche, Gilead, Abbvie, Sanofi, Molmed; lecturer fees from AstraZeneca, Janssen, Roche, Gilead, Abbvie, Sanofi, Novartis; research support from Genzyme, Sanofi, GSK, Novartis, Abbvie. OH - consultancy honoraria from $\mathrm{AB}$ Science; research support from $\mathrm{AB}$ Science, Celgene, Alexion, and Inatherys. DG-consultancy honoraria from Roche, Takeda, Iqone; lecturer fees from Abbvie, Celgene, Sanofi-Genzyme; research support from Takeda. NK-lecturer fees from Neovii, Sanofi, Novartis, Kiadis, Celgene, Amgen, Riemser, Chugai, Janssen; research support from Novartis, Celgene, Riemser, Neovii. PD—consultancy for AbbVie, AstraZeneca, Gilead, Janssen, Novartis, Riemser, Roche; speakers bureau for AbbVie, Gilead, Novartis, Riemser, Roche; research support from Neovii and Riemser. The remaining authors declared no conflict of interest.

Publisher's note Springer Nature remains neutral with regard to jurisdictional claims in published maps and institutional affiliations.

Open Access This article is licensed under a Creative Commons Attribution 4.0 International License, which permits use, sharing, adaptation, distribution and reproduction in any medium or format, as long as you give appropriate credit to the original author(s) and the source, provide a link to the Creative Commons license, and indicate if changes were made. The images or other third party material in this article are included in the article's Creative Commons license, unless indicated otherwise in a credit line to the material. If material is not included in the article's Creative Commons license and your intended use is not permitted by statutory regulation or exceeds the permitted use, you will need to obtain permission directly from the copyright holder. To view a copy of this license, visit http://creativecommons. org/licenses/by/4.0/.

\section{References}

1. Mato AR, Nabhan C, Barr PM, Ujjani CS, Hill BT, Lamanna N, et al. Outcomes of CLL patients treated with sequential kinase inhibitor therapy: a real world experience. Blood. 2016;128:2199-205.

2. Jones JA, Mato AR, Wierda WG, Davids MS, Choi M, Cheson $\mathrm{BD}$, et al. Venetoclax for chronic lymphocytic leukaemia progressing after ibrutinib: an interim analysis of a multicentre, openlabel, phase 2 trial. Lancet Oncol. 2018;19:65-75.

3. Coutre S, Choi M, Furman RR, Eradat H, Heffner L, Jones JA, et al. Venetoclax for patients with chronic lymphocytic leukemia who progressed during or after idelalisib therapy. Blood. 2018;131:1704-11.

4. Roberts AW, Ma S, Kipps TJ, Coutre SE, Davids MS, Eichhorst $\mathrm{B}$, et al. Efficacy of venetoclax in relapsed chronic lymphocytic leukemia is influenced by disease and response variables. Blood. 2019; 134:111-22.

5. Mato AR, Hill BT, Lamanna N, Barr PM, Ujjani CS, Brander $\mathrm{DM}$, et al. Optimal sequencing of ibrutinib, idelalisib, and venetoclax in chronic lymphocytic leukemia: results from a multicenter study of 683 patients. Ann Oncol. 2017;28:1050-6.

6. Woyach JA. Treatment-naive CLL: lessons from phase 2 and phase 3 clinical trials. Hematol Am Soc Hematol Educ Program. 2019;2019:476-81.
7. Mato AR, Roeker LE, Jacobs R, Hill BT, Lamanna N, Brander D, et al. Assessment of the efficacy of therapies following venetoclax discontinuation in CLL reveals BTK inhibition as an effective strategy. Clin Cancer Res. 2020;26:3589-96.

8. Louie CY, DiMaio MA, Matsukuma KE, Coutre SE, Berry GJ, Longacre TA. Idelalisib-associated enterocolitis: clinicopathologic features and distinction from other enterocolitides. Am J Surg Pathol. 2015;39:1653-60.

9. Coutre SE, Barrientos JC, Brown JR, de Vos S, Furman RR, Keating MJ, et al. Management of adverse events associated with idelalisib treatment: expert panel opinion. Leuk Lymphoma. 2015;56:2779-86.

10. Dohner H, Stilgenbauer S, Benner A, Leupolt E, Krober A, Bullinger L, et al. Genomic aberrations and survival in chronic lymphocytic leukemia. N Engl J Med. 2000;343:1910-6.

11. Dreger P, Corradini P, Kimby E, Michallet M, Milligan D, Schetelig J, et al. Indications for allogeneic stem cell transplantation in chronic lymphocytic leukemia: the EBMT transplant consensus. Leukemia. 2007;21:12-7.

12. Bacigalupo A, Ballen K, Rizzo D, Giralt S, Lazarus H, Ho V, et al. Defining the intensity of conditioning regimens: working definitions. Biol Blood Marrow Transplant. 2009;15:1628-33.

13. Gray R. A class of k-sample tests for comparing the cumulative incidence of a competing risk. Ann Stat. 1988;16:1141-54.

14. Ali K, Soond DR, Pineiro R, Hagemann T, Pearce W, Lim EL, et al. Inactivation of $\mathrm{PI}(3) \mathrm{K}$ p110delta breaks regulatory T-cellmediated immune tolerance to cancer. Nature. 2014;510:407-11.

15. Okkenhaug K, Graupera M, Vanhaesebroeck B. Targeting PI3K in cancer: impact on tumor cells, their protective stroma, angiogenesis, and immunotherapy. Cancer Discov. 2016;6:1090-105.

16. Schetelig J, Link CS, Stuhler G, Wagner EM, Hanel M, Kobbe G, et al. Anti-CD20 immunotherapy as a bridge to tolerance, after allogeneic stem cell transplantation for patients with chronic lymphocytic leukaemia: results of the CLLX4 trial. Br J Haematol. 2019;184:833-6.

17. Dreger P, Michallet M, Bosman P, Dietrich S, Sobh M, Boumendil A, et al. Ibrutinib for bridging to allogeneic hematopoietic cell transplantation in patients with chronic lymphocytic leukemia or mantle cell lymphoma: a study by the EBMT Chronic Malignancies and Lymphoma Working Parties. Bone Marrow Transplant. 2019;54:44-52.

18. Shadman M, Maloney DG, Storer B, Sandmaier BM, Chauncey TR, Smedegaard Andersen N, et al. Rituximab-based allogeneic transplant for chronic lymphocytic leukemia with comparison to historical experience. Bone Marrow Transplant. 2020;55:172-81.

19. Sellner L, Schetelig J, Koster L, Choi G, Blaise D, Beelen D, et al. Idelalisib exposure before allogeneic stem cell transplantation in patients with follicular lymphoma: an EBMT survey. Bone Marrow Transplant. 2020. https://doi.org/10.1038/s41409-0200946-x.

20. Dreger P, Koster L, Passweg JR, Collin M, Scheid C, Charbonnier A, et al. Safety and efficacy of idelalisib treatment of chronic lymphocytic leukemia (CLL) or lymphoma relapsing after allogeneic hematopoietic cell transplantation (alloHCT): a survey by the EBMT chronic malignancies and lymphoma working parties. Blood. 2017;130:3273.

21. Dreger P, Ghia P, Schetelig J, van Gelder M, Kimby E, Michallet $M$, et al. High-risk chronic lymphocytic leukemia in the era of pathway inhibitors: integrating molecular and cellular therapies. Blood. 2018;132:892-902.

22. Andersen NS, Bornhauser M, Gramatzki M, Dreger P, Vitek A, Karas M, et al. Reduced intensity conditioning regimens including alkylating chemotherapy do not alter survival outcomes after allogeneic hematopoietic cell transplantation in chronic lymphocytic leukemia compared to low-intensity non-myeloablative conditioning. J Cancer Res Clin Oncol. 2019;145:2823-34. 
23. Schetelig J, de Wreede LC, van Gelder M, Andersen NS, Moreno $\mathrm{C}$, Vitek A, et al. Risk factors for treatment failure after allogeneic transplantation of patients with CLL: a report from the European
Society for Blood and Marrow Transplantation. Bone Marrow Transplant. 2017;52:552-60.

\section{Affiliations}

Johannes Schetelig ${ }^{1,2} \cdot$ Patrice Chevallier $^{3} \cdot$ Michel van Gelder ${ }^{4} \cdot$ Jennifer Hoek $^{5} \cdot$ Olivier Hermine $^{6}$. Ronjon Chakraverty ${ }^{7}$ Paul Browne ${ }^{8} \cdot$ Noel Milpied $^{9} \cdot$ Michele Malagola $^{10} \cdot$ Gerard Socié $^{11} \cdot$ Julio Delgado $^{12}$. Eric Deconinck ${ }^{13}$. Ghandi Damaj ${ }^{14}$. Sebastian Maury ${ }^{15}$. Dietrich Beelen ${ }^{16}$. Stéphanie Nguyen Quoc ${ }^{17}$.

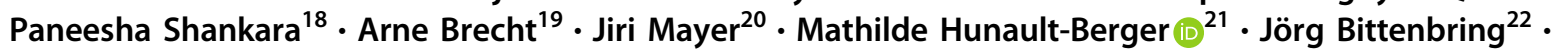
Catherine Thieblemont ${ }^{23} \cdot$ Stéphane Lepretre ${ }^{24} \cdot$ Henning Baldauf $^{2} \cdot$ Liesbeth C. de Wreede $^{25} \cdot$ Olivier Tournilhac $^{26}$. Ibrahim Yakoub-Agha ${ }^{27} \cdot$ Nicolaus Kröger $\mathbb{1}^{28} \cdot$ Peter Dreger $\mathbb{C}^{29}$

1 Medical Clinic I, University Hospital, Dresden, Germany

2 DKMS, Dresden, Germany

3 CHU Nantes, Nantes, France

4 University Hospital Maastricht, Maastricht, The Netherlands

5 EBMT Data Office, Leiden, The Netherlands

6 Department of Hematology, Necker Hospital and INSERM U1163 Imagine Institute, University of Paris, Paris, France

7 Cancer Institute and Institute of Immunity and Transplantation, University College London Hospital, London, UK

8 Hope Directorate, Dublin, Ireland

9 CHU Bordeaux, Pessac, France

10 Bone Marrow Transplant Unit, ASST-Spedali Civili di Brescia, University of Brescia, Brescia, Italy

11 Hopital St. Louis, Paris, France

12 Hospital Clinic, Barcelona, Spain

13 Hopital Jean Minjoz, Besancon, France

14 Centre Hospitalier-Universitaire, Institut d'Hématologie, Normandie University, Caen, France

15 Service d'Hématologie Clinique et de Thérapie Cellulaire Creteil, CHU Henri Mondor, Créteil, France
16 University Hospital, Essen, Germany

17 Hopital la Pitié-Salpêtrière, Universite Paris IV, Paris, France

18 Birmingham Heartlands Hospital, Birmingham, UK

19 Helios Dr. Horst Schmidt Kliniken, Wiesbaden, Germany

20 University Hospital Brno, Brno, Czech Republic

21 Maladies du Sang, CHU Angers, Angers, France

22 University of Saarland, Homburg, Saar, Germany

23 Hôpital St. Louis, Paris, France

24 Inserm U1245 and Department of Hematology, Centre Henri Becquerel, Normandie University, Rouen, France

25 Department of Medical Statistics \& Bioinformatics, Leiden University Medical Center, Leiden, The Netherlands

26 Service Therapie Cellulaire \& Hematologie Cliniquer, Centre Hospitalier Universitaire, Clermont Ferrand, France

27 Centre Hospitalier Universitaire de Lille, LIRIC, INSERM U995, Université de Lille, Lille, France

28 University Hospital Eppendorf, Hamburg, Germany

29 University of Heidelberg, Heidelberg, Germany 